\title{
Assessment of Anthelmintic Property and Insilico study of phytocompounds in roots of Dechaschistia crotonifolia Wight \& Arn.
}

Raveesha Peeriga ( $\nabla$ drprsha@gmail.com )

V V INSTITUTE OF PHARMACEUTICAL SCIENCES https://orcid.org/0000-0003-4827-6076

Keerthi Priyanka Adarapu

V. V. Institute of Pharmaceutical Sciences

Kavya Sri Sanivarapu

V. V. Institute of Pharmaceutical Sciences

Jyothsna Kanumuri

V. V. Institute of Pharmaceutical Sciences

Rikith Swamy Akunuri

V. V. Institute of Pharmaceutical Sciences

Lakshmana Rao Atmakuri

V. V. Institute of Pharmaceutical sciences

\section{Research Article}

Keywords: Dechaschistia crotonifolia Wight \& Arn., Ebanaceae, Pheretima and Anthelmintic, Docking, Lipinski rule

Posted Date: January 4th, 2022

DOI: https://doi.org/10.21203/rs.3.rs-1198187/v1

License: (c) (i) This work is licensed under a Creative Commons Attribution 4.0 International License. Read Full License 


\section{Abstract}

Background:Worm infections in developing countries were reported high. Phytoconstituents have been a vital role for the treatment of many ailments. The current study was aimed assess for anthelmintic activity of different root extracts of Dechaschistia crotonifolia Wight \& Arn. belongs to the family Ebanaceae against Pheretima posthuma. Further Insilico study was carried out for phytocompounds present in Dechaschistia.

Results: The chloroform, ethylacetate and ethanol extract of Dechaschistia crotonifolia Wight \& Arn. were considered for the study of anthelmintic property on earthworms at concentrations $20 \mathrm{mg} / \mathrm{ml}, 40 \mathrm{mg} / \mathrm{ml}$ and $60 \mathrm{mg} / \mathrm{ml}$. During this study, the parameters paralysis time (Pt) and Death Time (Dt) of adult Indian earthworms was observed. As a standard and control Albendazole $10 \mathrm{mg} / \mathrm{ml}$ and $2 \%$ Tween 80 in distilled water were taken respectively. The study resulted that ethanolic extract was significant when compared with the Albendazole $10 \mathrm{mg} / \mathrm{ml}$. Docking studies revealed the all phytocompounds in Dechaschistia shown binding affinity, however comparatively scopoletin and stigmasterol had shown a good binding affinitiy about $-7.7 \mathrm{Kcal} / \mathrm{mol}$ and $-7.6 \mathrm{Kcal} / \mathrm{mol}$ compared to standard drug Albendazole which was shown about $-8.7 \mathrm{Kcal} / \mathrm{mol}$.

Conclusion: The study revealed that the ethanol extract of Dechaschistia crotonifolia Wight \& Arn. at a concentration of $60 \mathrm{mg} / \mathrm{ml}$ exhibited a stronger anthelmintic property compared to Albendazole $10 \mathrm{mg} / \mathrm{ml}$. A dose dependent anthelmintic activity is exerted by all the extracts in an ascending manner Chloroform<Ethyl acetate<Ethanol. These observations were made evidenced by docking studies of phytocompounds in Dechaschistia as the phytocompounds were shown excellent docking score when compared with standard Albendazole.

\section{Background}

Diseases caused by helminths are chronic. Helminthiasis is infested to human beings with worm's likely pinworm, round worm or tapeworm [1]. The diseases caused by parasites results in morbidity and leads to the condition onchocorciasis and Schistosomiasis. The more number of worm infections has been reported in developing countries due to lack of proper hygienic conditions. By considering the affordability and various side effects of synthetic compounds, a preferability towards herbal medicines were choosen. An adult Indian earthworm Pheretima posthuma is selected for assessment of anthelmintic property as it shows similarity in anatomy and physiology of round worm parasites resides in intestine of human beings.

Dechaschistia crotonifolia Wight \& Arn. is a shrub consists of dense whitish wooly on stems and branches [2]. The leaves are in ovate lance shaped measures $3-6 \mathrm{~cm}$ long, 2-4 cm width. The base of leaf is heart shaped or rounded, pointed apex with coarsely toothed margins. Leaves are velvety, bears $1.5 \mathrm{~cm}$ long stalks. It represents with Yellow flowers with dark maroon centered in single leaf axils. The Sepal cup 
is bell in shape, $1-1.5 \mathrm{~cm}$ long cup encloses capsules and seeds. The seeds are kidney-shaped. It is most common in the deciduous forests of peninsular India. Flowering takes place in the month of March to June.

Earlier preliminary phytochemical assessment was made [3, 4]. As the Investigations on Dechaschistia crotonifolia Wight \& Arn. were very limited based on literature survey and existence of insecticidal activity in the family Ebanaceae. The current study is focussed to evaluate anthelmintic activity of three extracts viz., Chloroform, Ethylacetate and Ethanol extract of Dechaschistia crotonifolia Wight \& Arn.

\section{Methods}

\section{Plant material}

The roots of Dechaschistia crotonifolia Wight \& Arn. belonging to the family to Ebaenaceae were collected from surroundings of Tirumala, Andhra Pradesh, India in the month of June and it was authenticated by Dr. K. Madhava Chetty, Head of Department, Department of Botany, SV University, Tirupati. Voucher Specimen (PHCOG/VVIPS/056) were preserved. The roots of Decaschistia crotonifolia were shade dried, powdered and stored in well closed container.

\section{Preparation of Extracts}

About 300gm of dried root powdered drug of Dechaschistia crotonifolia Wight \& Arn. was extracted by successive solvent extraction using chloroform, ethylacetate and ethanol by Soxhlet extraction for 72 hours. The extract was made concentrated by rotary evaporator and placed in desiccator for further use.

\section{Evaluation of Anthelmintic Property}

Anthelmintic property of chloroform, ethylacetate and ethanol root extracts of Dechaschistia crotonifolia Wight \& Arn. was examined by using an Indian earthworm Pheretima posthuma [5,6]. Choosing of Pheretima posthuma is made as it resembles identical towards anatomy and physiology of round worm parasite which occurs in alimentary tract of Homosapiens.

Adult earth worms measures an average size $4-7 \mathrm{~cm}$ in length and $0.3-0.7 \mathrm{~cm}$ of width was collected from medicinal garden of V. V. Institute of Pharmaceutical Sciences and proper washings are carried out to remove extraneous matter. The extract at concentration of $30 \mathrm{mg} / \mathrm{ml}, 60 \mathrm{mg} / \mathrm{ml} \& 80 \mathrm{mg} / \mathrm{ml}$ was used to examine the time of paralysis $(\mathrm{Pt})$ and Death (Dt). The selected earthworms are categorized into 11 groups of 6 each viz., control group treated with $2 \%$ Tween 80 in distilled water, 9 Test groups treated with concentrations of $30 \mathrm{mg} / \mathrm{ml}, 60 \mathrm{mg} / \mathrm{ml} \& 80 \mathrm{mg} / \mathrm{ml}$ of each Chloroform, Ethylacetate and Ethanol extract of Dechaschistia crotonifolia Wight \& Arn. and standard group treated with $10 \mathrm{mg} / \mathrm{ml}$ concentration of Albendazole. Earthworms are treated with volume of $10 \mathrm{ml}$ of each concentration of standard, control and test solutions respectively. The time taken for Paralysis (Pt) and Death (Dt) was noted.

\section{Docking studies}




\section{ADME Analysis}

Pharmacokinetic Evaluation of phytoconstituents is necessary as it effects binding of compounds in specific active target site $[7,8]$. Prior docking studies of Phytochemicals, it is very much needed to qualify drug-likeness test, i.e., they have to obey Lipinski rule[9]. The canonical smiles of phytocompounds Parvifloral A (PubChem CID: 90470346), Syriacusin A (PubChem CID: 9991528), Syriacusin B (PubChem CID: 10015552), Syriacusin C (PubChem CID: 10105245), Scopoletin (PubChem CID: 5280460), Stigmasterol (PubChem CID: 5280794) and Standard drug Albendazole (PubChem CID: 2082)was obtained from Pubchem (pubchem.ncbi.nlm.nih.gov) predicted their drug likeness test using SwissADME (SwissADME) and their physico chemical parameters.

\section{In-silico study}

For molecular docking study $[10,11,12]$ Autodock vina is used for prediction of potent phytocompounds of Dechaschistia viz., Parvifloral, Syriacusin A, Syriacusin B, Syriacusin C, Scopoletin and Stigmasterol against active site of $\beta$-tubulin. The chemical structures of phytoconstituents Parvifloral, Syriacusin A, Syriacusin B, Syriacusin C, Scopoletin and Stigmasterol were obtained from Pubchem Project Database shown in Fig. 3. They were structurally plotted in Discovery Studio Biovia. The 3D structure of protein $\beta$ tubulin (PDB ID: 1oj0) is collected from Protein Data Bank (www.rcsb.org/pdb) shown in Fig. 2. The x, y \& $\mathrm{z}$ attributes along with radius is noted. Further the structure is prepared by removing water, adds up polar hydrogen bond and made torsion free.

\section{Statistical Analysis}

The values were represented as mean \pm S.D; via one-way ANOVA. The analysis was carried out by using Graph pad Prism (Version 3, U.S.A.) software program. $\mathrm{P}<0.05$ was taken into statistically significant.

\section{Results}

\section{Anthelmintic activity}

Table 1, 2 \& Fig 1 represents the mean time of Paralysis (Pt) and Death (Dt) by various concentration of chloroform, ethylacetate and ethanol extract against earthworms. After scrutinizing the results obtained from experimental methods it was found that the higher concentrations of ethanol shown a faster paralytic and shorter death time of all earthworms.

\section{ADME analysis}

All the phytocompounds shown the zero violation except stigmasterol as it shown 1 violation. The standard drug Albendazole also showed zero violation. The results were depicted in table 4. 


\section{In-silico Study}

Docking revealed that out of 6 phytocompounds Parvifloral, Syriacusin A, Syriacusin B, Syriacusin C, Scopoletin and Stigmasterol with protein $\beta$-tubulin had shown docking scores of $-6.3 \mathrm{kcal} / \mathrm{mole},-6.9$ $\mathrm{kcal} / \mathrm{mole},-6.0 \mathrm{kcal} / \mathrm{mole},-6.7 \mathrm{kcal} / \mathrm{mole},-7.7 \mathrm{kcal} / \mathrm{mole},-8.7 \mathrm{kcal} / \mathrm{mole}$ and standard drug Albendazole shown at $-7.6 \mathrm{kcal} / \mathrm{mole}$. The phytocompounds had shown hydrogen bond interactions with aminoacid and the results discloses the hydrogen bond interactions are associated with aminoacids in each ligand \& protein complex except with Syriacusin C. The outcomes are depicted in table 3 and the complexes are made visualized in Fig no 4.

\section{Discussion:}

Helmenthiasis is considered as disease in south Asia including India. Hence and investigation in larger no on alternative sources are made for their anthelmintic acitivity [13-17]. The considerations of anthelmintic activity due to flavonoids and steroids were stated earlier. The flavonoids biochanin A and genistein was shown effective anthlemintic activity against Aspiculuris tetraptera. Anthelmintic tests according to the procedure of Hounzangbe Adote et al were conducted for the phytocompounds against Haemonchus contortus. The best activity was obtained with flavonoids [18].

Aqueous extract of whole plant of Amaranthus spinosus had exerted anthlemintic activity against Pheritima posthuma in dose dependent manner due to presence of steroids and flavonoids [19]. The study aimed to evaluate anthelmintic activity of chloroform ethylacetate and ethanolic root extract of Dechaschistia crotonifolia. The pharmacognositical investigations were carried out. The qualitative chemical screening of Dechaschistia was studied and revealed the presence of steroids, flavonoids and tannins more in ethanolic extract. In earlier studies Trinorcadalenes, parviflorals A, Syriacusin A, B \& C, Scopoletin and Stigmasterol were isolated and their structures along with resonance were elucidated by ${ }^{1} \mathrm{H}$ and ${ }^{13} \mathrm{C}$ NMR spectroscopy [4].

The chloroform $(44.00 \pm 0.89,99.00 \pm 1.26)$, ethylacetate $(32.83 \pm 87.16 \pm 0.75)$ and ethanol extract $(21.00 \pm 0.89,25.33 \pm 0.81)$ of Dechaschistia crotonifolia Wight \& Arn. shown the anthelmintic activity at the concentration of $80 \mathrm{mg} / \mathrm{ml}$. Amongst Ethanolic extract had taken shorter duration of time to kill or paralyze and comparatively with standared drug Albendazole it is mere the same. All the extracts at $20 \mathrm{mg} / \mathrm{ml}$ were taken too long to paralyze or to kill the adult earthworms.

It is possible to learn the mechanism of action of phytoconstituents in virtual screening methods. These methods make to design phytoremedies for various diseases. A various phytocompounds for antihelmintic activity was investigated [20,21,22]. Docking studies signify the fact that out of 6 phytochemicals stigmasterol and scopoletin shown $-8.7 \mathrm{kcal} / \mathrm{mole}$ and syriacusin B with least among 6 phytochemicals was $-6 \mathrm{kcal} / \mathrm{mole}$. The docking score of scopoletin and stigmasterol had shown at -7.6 $\mathrm{kcal} / \mathrm{mole}$ and $-8.7 \mathrm{kcal} / \mathrm{mole}$ representing good binding affinity between phytocompound and $\beta$-tubulin than between the protein ( $\beta$-tubulin) and standard drug albendazole, shown the docking score at -7.6 
$\mathrm{kcal} / \mathrm{mole}$. ADME analysis of phytocompounds and standard revealed that zero violation of drug likeness and obeyed the Lipinski rule.

\section{Discussion:}

Helmenthiasis is considered as disease in south Asia including India. Hence and investigation in larger no on alternative sources are made for their anthelmintic acitivity [13-17]. The considerations of anthelmintic activity due to flavonoids and steroids were stated earlier. The flavonoids biochanin $A$ and genistein was shown effective anthlemintic activity against Aspiculuris tetraptera. Anthelmintic tests according to the procedure of Hounzangbe Adote et al were conducted for the phytocompounds against Haemonchus contortus. The best activity was obtained with flavonoids [18].

Aqueous extract of whole plant of Amaranthus spinosus had exerted anthlemintic activity against Pheritima posthuma in dose dependent manner due to presence of steroids and flavonoids [19]. The study aimed to evaluate anthelmintic activity of chloroform ethylacetate and ethanolic root extract of Dechaschistia crotonifolia. The pharmacognositical investigations were carried out. The qualitative chemical screening of Dechaschistia was studied and revealed the presence of steroids, flavonoids and tannins more in ethanolic extract. In earlier studies Trinorcadalenes, parviflorals A, Syriacusin A, B \& C, Scopoletin and Stigmasterol were isolated and their structures along with resonance were elucidated by

${ }^{1} \mathrm{H}$ and ${ }^{13} \mathrm{C}$ NMR spectroscopy [4].

The chloroform $(44.00 \pm 0.89,99.00 \pm 1.26)$, ethylacetate $(32.83 \pm 87.16 \pm 0.75)$ and ethanol extract $(21.00 \pm 0.89,25.33 \pm 0.81)$ of Dechaschistia crotonifolia Wight \& Arn. shown the anthelmintic activity at the concentration of $80 \mathrm{mg} / \mathrm{ml}$. Amongst Ethanolic extract had taken shorter duration of time to kill or paralyze and comparatively with standared drug Albendazole it is mere the same. All the extracts at $20 \mathrm{mg} / \mathrm{ml}$ were taken too long to paralyze or to kill the adult earthworms.

It is possible to learn the mechanism of action of phytoconstituents in virtual screening methods. These methods make to design phytoremedies for various diseases. A various phytocompounds for antihelmintic activity was investigated [20,21,22]. Docking studies signify the fact that out of 6 phytochemicals stigmasterol and scopoletin shown $-8.7 \mathrm{kcal} / \mathrm{mole}$ and syriacusin B with least among 6 phytochemicals was $-6 \mathrm{kcal} / \mathrm{mole}$. The docking score of scopoletin and stigmasterol had shown at -7.6 $\mathrm{kcal} / \mathrm{mole}$ and $-8.7 \mathrm{kcal} /$ mole representing good binding affinity between phytocompound and $\beta$-tubulin than between the protein ( $\beta$-tubulin) and standard drug albendazole, shown the docking score at -7.6 $\mathrm{kcal} / \mathrm{mole}$. ADME analysis of phytocompounds and standard revealed that zero violation of drug likeness and obeyed the Lipinski rule.

\section{Conclusions}

The current study aimed in evaluating anthelmintic activity of Dechaschistia crotonifolia. The test revealed a significant anthelmintic activity of ethanolic root extract and the remaining extracts were also 
shown but it is considered as dose dependent manner. This activity is supported by docking studies. Docking studies shown that binding poses and distance measurement of $\beta$-tubulin complexes parviflorals A, Syriacusin A, Syriacusin B \& Syriacusin C, Scopoletin and Stigmasterol reveals that the lead phytocompounds were in near proximity associated with most active site of aminoacids. This confirms the phytocompounds present in Dechaschistia need to investigate for the discovery of new generation of drugs as they will be remedies against organisms causing helminths.

\section{Declarations}

\section{Ethics approval and consent to participate}

This study did not take include samples from humans. So no content was required.

\section{Consent for publication}

Not applicable

\section{Availability of data and materials}

All data generated or analyzed during the study are included in this article.

\section{Competing interests}

Authors declare that they have no competing interest.

\section{Funding}

Not Applicable.

\section{Authors' Contributions}

$\mathrm{RP}$ is the designer of the research project and supervised the work. LRA, KPA, KSS, JK and RSA participated in study implementation. All the authors participated in the datat collection, reading and validation of the manuscript.

\section{Acknowledgements}

I acknowledge to the management of V. V. Institute of Pharmaceutical Sciences for their support during the study.

\section{Plant Authentication}

The plants were used in this study were aunthenticated at Sri Venkateswara University under the number PHCOG/VVIPS/056 for Dechaschistia crotonifolia. 


\section{Abbreviations}

Pt: Paralysis time; Dt: Death time; CEDC: Chloroform extract of Dechaschistia crotonifolia; EAEDC: Ethyl acetate extract of Dechaschistia crotonifolia; EEDC: Ethanol extract of Dechaschistia crotonifolia.

\section{References}

1. Mahesh Bandappa M, Shashikant Chaburao D, Prasad Govindrao J (2015) Helminthiasis and medicinal plants: a review. Asian Pacific Journal of Tropical Disease 5(3): 175-180.

2. Raveesha P, Lakshmana Rao A, Ooha Deepika G, Divya G, Monika Ch, Bhargavi G, (2020) Pharmacognostical study and preliminary phytochemical investigation of Dechaschistia crotonifolia wight \& arn. J. Global Trends Pharm Science 11 (4): 8782 - 8790.

3. Raveesha P, Lakshmana Rao A, Rohitha V, Jaswitha T, Prasannajaneyulu V, Reshma Sk (2021) Evaluation of antibacterial activity of dechaschistia crotonifolia. J. Global Trends Pharm Sci. 12 (4): $9833-9835$.

4. Nikhom W, Somdej K, Kwanjai K, Palangpon K, Samran P, Stephen GP (2013) Parviflorals A-F, trinorcadalenes and bis-trinorcadalenes from the roots of Decaschistia parviflora. Phytochemistry 95: 368-374.

5. Barnali G, Bibhuti Bhusan K, Nilutpal Sharma B, Priyanka Y (2014) In vitro antihelmintic activity of bark extract of cinnamomum bejolghota (buch. -Ham.) in Indian adult earthworm (Pheretima posthuma) Asian pacific journal of tropica disease. 4(2): S924-S927.

6. Nagaraju K, Anusha D, Chitra K, Ravibabu K (2019) Preliminary analysis of phytoconstituents and evaluation of anthelmintic property of Cayratia auriculata (invitro). Maedica-a Journal of Clinical Medicine 14(4): 350-356.

7. Yuliya SP, Lina OP, Victoriya AG (2019) Docking studies of biologically active substances from plant extracts with anticonvulsant activity. Journal of Applied Pharmaceutical Science 9(01): 066-072.

8. Selamawit Z, Teka F and Solomon A (2017) In Vitro Anthelmintic Activity of Crude Extracts of Aerial Parts of Cissus quadrangularis L. and Leaves of Schinus molle L. against Haemonchus contortus. BioMed Research International 1(6): 1-6.

9. Arkajyoti P, Adnan Md, Majumder M, Niloy K, Muntasir M, Rahman Md, Akash Kumar R, Rahman N, Nazim Uddin Chy Md and Shah Hafez Kabir Paul Md (2018) Anthelmintic activity of Piper sylvaticum Roxb. (Family: Piperaceae): In vitro and in silico studies. Clinical Phytoscience 4(17): 1-7.

10. Syed Mohd Danish R, Shazi S, Haneef Md (2013) A Simple click by click protocol to perform docking: autodock 4.2 made easy for non-bioinformaticians. Excli Journal 12: 831-857.

11. Uzma S, Shingraf Z, Sana K, Fareeha A, Furqan Akhtar M, Bashir A, Chemical characterization, docking studies, antiarthritic activity and acute oral toxicity of convolvulus arvensis L. leaves Asian pacific journal of tropical biomedicine 10(10): 442-451.

12. Sravani T, Padmaa MP Shruthi SD (2014) Insilico and invitro anthelmintic activity of $\beta$-sitosterol isolated from rhizomes of Hedychium spicatum Buch.-Ham. Indian journal of natural products and 
resources 5(3): 258-261.

13. Kazi Nahid A, Palash K, Abhijit D, Shamima Nasrin A, Sharmin Akter S, Mohammad Mafruhi S (2014) Evaluation of antibacterial and anthelmintic activities with total phenolic contents of piper betel leaves. Avicenna journal of phytomedicine 4(5): 320-329.

14. Swastiprava D, Sugimani M, Susanta Kumar B, Tikendrajit B, Ramesh S, Rajkumari Supriya D, Rikina Ch, Sanjeet Kumar (2021) Evaluation of Antihelminthic Activity of Bixa orellana. Asian Pacific Journal of Health Sciences 8(4): 228-233.

15. Satyendra RV, Vishnumurthy KA, Vagdevi HM, Rajesh KP, Manjunatha H, Shruthi A (2011) Synthesis, in vitro antioxidant, anthelmintic and molecular docking studies of novel dichloro substituted benzoxazole-triazolo-thione derivatives. European Journal of Medicinal Chemistry 46: 3078-3084.

16. Akhtar MS, Zafar I, Khan MN, Lateef Md. (2000) Athelmintic activity of medicinal plants with particular reference to their use in animals in the Indo-Pakistan subcontinent. Small ruminant research. 38: 99-107.

17. Placide MT, Ele'onore YL, Anthony L, Sylvie HA, Sime'on FK, Joachim DGB (2021) Anthelmintic flavonoids and other compounds from Combretum glutinosum Perr. ex DC (Combretaceae) leaves. Acta Crystallographica C77: 505-512.

18. Virgínia CDS, Mário GDC, Hélcio RB, Sandra LCS (2008) Anthelmintic activity of flavonoids isolated from roots of Andira anthelmia (Leguminosae). Brazilian Journal of Pharmacognosy 18(4): 573-576.

19. Manik B, Subrata C, Pranabesh C (2010) Evaluation of anthelmintic and antiinflammatory activity of amaranthus spinosus linn. International Journal of Current Pharmaceutical Research 2(4): 44-47.

20. Megha BJ, Rajashri SS, Mohan MR, Maruti JD, Kailas DS, Gajanan SR (2018) Water-mediated ynthesis of anthelmintic piperidinols and their molecular docking studies chemistry select 3: 5581 5587.

21. Karla L RB, Carolina RS, Valdenice FS, Rafael CS, Renato RR, Ana LE S, Raquel OP, Plínio D, Bruno AM R, Alexandra MS S, Livio M CJ, Claudener ST (2018) Structural analysis and anthelmintic activity of Canavalia brasiliensis lectin reveal molecular correlation between the carbohydrate recognition domain and glycans of Haemonchus contortus. Molecular \& Biochemical Parasitology 225: 67-72.

22. Grace B, Errini D, Dharitri D, Ramesh Ch, Arun K and Ghanashyam B (2020) Coumarin-based Trisubstituted Methanes as Potent Anthelmintic: Synthesis, Molecular Docking and in vitro efficacy. J. Chem. Science 132(40): 1-12.

\section{Tables}

Table 1 Time taken to paralyze by P. posthuma treated with CEDC, EAEDC and EEDC 


\begin{tabular}{|c|c|c|c|c|}
\hline \multirow[t]{3}{*}{ S. No. } & \multirow[t]{3}{*}{ Drugs Treatment } & \multicolumn{3}{|c|}{ Time taken for Paralysis (Pt) } \\
\hline & & \multicolumn{3}{|c|}{ Dose taken at different Concentrations: } \\
\hline & & $20 \mathrm{mg} / \mathrm{ml}$ & $40 \mathrm{mg} / \mathrm{ml}$ & $80 \mathrm{mg} / \mathrm{ml}$ \\
\hline 1 & $20 \%$ Tween & 0 & 0 & 0 \\
\hline 1. & Albendazole & $25.53 \pm 0.51$ & $25.53 \pm 0.51$ & $25.56 \pm 0.53$ \\
\hline 1. & Chloroform Extract (CEDC) & $94.83 \pm 1.16$ & $64.33 \pm 1.21$ & $44.00 \pm 0.89 * \star$ \\
\hline 1. & Ethylacetate Extract (EAEDC) & $81.66 \pm 1.63$ & $47.00 \pm 1.26 * *$ & $32.83 \pm 0.75^{\star \star}$ \\
\hline 1. & Ethanol Extract (EEDC) & $51.16 \pm 1.16^{\star \star}$ & $34.83 \pm 0.75^{\star \star}$ & $21.00 \pm 0.89 * \star$ \\
\hline
\end{tabular}

*All the values were expressed in Mean \pm Standard Deviation. Statistical significance $P<0.05$

Table 2 Time taken to kill $P$. posthuma treated with CEDC, EAEDC and EEDC

\begin{tabular}{|llll|}
\hline Drugs Treatment & \multicolumn{2}{l}{ Time taken for Death (Dt) } \\
\cline { 2 - 4 } & \multicolumn{2}{l}{ Doses taken at Concentrations: } \\
\cline { 2 - 4 } & $20 \mathrm{mg} / \mathrm{ml}$ & $40 \mathrm{mg} / \mathrm{ml}$ & $80 \mathrm{mg} / \mathrm{ml}$ \\
\hline $20 \%$ Tween & 0 & 0 & 0 \\
\hline Albendazole & $25.53 \pm 0.51$ & $25.53 \pm 0.51$ & $25.52 \pm 0.52$ \\
\hline Chloroform Extract (CEDC) & $162.83 \pm 1.72$ & $148.5 \pm 1.04$ & $99.00 \pm 1.26$ \\
\hline Ethylacetate Extract (EAEDC) & $133.66 \pm 1.03$ & $121.16 \pm 0.75$ & $87.16 \pm 0.75^{\star *}$ \\
\hline Ethanol Extract (EEDC) & $49.50 \pm 1.04^{\star *}$ & $33.33 \pm 1.21^{\star *}$ & $20.33 \pm 0.81^{\star \star}$ \\
\hline
\end{tabular}

*All the values were expressed in Mean \pm Standard Deviation. Statistical significance $P<0.05$

Table 3 Docking Simulation of $\beta$-tubulin and Phytocompounds 


\begin{tabular}{|c|c|c|c|}
\hline $\begin{array}{l}\text { S. } \\
\text { No. }\end{array}$ & Phytocompounds & $\begin{array}{l}\text { Binding } \\
\text { Energy } \\
\text { (kcal/mole) }\end{array}$ & Hydrogen bonds \\
\hline 1. & Parvifloral & -6.3 & ARG (A:318), GLU (A: 27) \& VAL (A:231) \\
\hline 1. & Syriacusin A & -6.9 & $\begin{array}{l}\text { ILE (A:24), PHE (A:20), GLN (A: 134), MET (A:233), TYR } \\
\text { (A:50), THR A:238), THR (A: } 237), \text { THR (A:136), HIS (A:6), } \\
\text { SER (A:165), LEU (A:250) and GLU (A:198) }\end{array}$ \\
\hline 1. & Syriacusin B & -6.0 & GLN (A:43), ARG (A:359), ARG (A: 318) and GLU (A:27) \\
\hline 1. & Syriacusin C & -6.7 & - \\
\hline 1. & Scopoletin & -7.7 & MET (A:233) \\
\hline 1. & Stigmasterol & -8.7 & GLN (A:43) \\
\hline 1. & Albendazole & -7.6 & SER (A:615) \& VAL (A:236) \\
\hline
\end{tabular}

Table 4 ADME Analysis of Phytocompounds

\begin{tabular}{|c|c|c|c|c|c|c|c|}
\hline $\begin{array}{l}\text { S. } \\
\text { No. }\end{array}$ & $\begin{array}{l}\text { Phyto } \\
\text { compounds }\end{array}$ & $\begin{array}{l}\text { Molecular } \\
\text { Weighta } \\
\left(\mathrm{g} / \mathrm{mol}^{\mathrm{a}}\right)\end{array}$ & $\begin{array}{l}\mathrm{H}- \\
\text { donor }^{b}\end{array}$ & $\begin{array}{l}\mathrm{H}- \\
\text { acceptorc }\end{array}$ & $\begin{array}{l}\text { Log P } \\
\text { Value }^{d}\end{array}$ & $\begin{array}{l}\text { Molar } \\
\text { Refractivitye }\end{array}$ & $\begin{array}{l}\text { Drug } \\
\text { likeness }\end{array}$ \\
\hline 1. & Parvifloral & 246.30 & 1 & 3 & 3.06 & 73.78 & 0 \\
\hline 1. & Syriacusin A & 232.23 & 2 & 4 & 2.24 & 64.84 & 0 \\
\hline 1. & Syriacusin B & 262.26 & 2 & 5 & 1.84 & 70.47 & 0 \\
\hline 1. & Syriacusin C & 230.22 & 1 & 4 & 2.53 & 62.39 & 0 \\
\hline 1. & Scopoletin & 192.17 & 1 & 4 & 1.52 & 51.00 & 0 \\
\hline 1. & Stigmasterol & 412.17 & 1 & 1 & 6.97 & 132.75 & 1 \\
\hline 1. & Albendazole & 265.33 & 3 & 2 & 2.39 & 73.22 & 0 \\
\hline
\end{tabular}




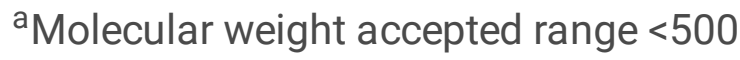

${ }^{\mathrm{b}}$ Hydrogen bond donor acceptable range $\leq 5$

${ }^{\mathrm{C}}$ Hydrogen bond acceptor acceptable range $\geq 10$

${ }^{\mathrm{d} H i g h}$ Lipophilicity (expressed as LogP, acceptable range $<5$

eMolar Refractivity should be between $40 \& 130$

\section{Figures}

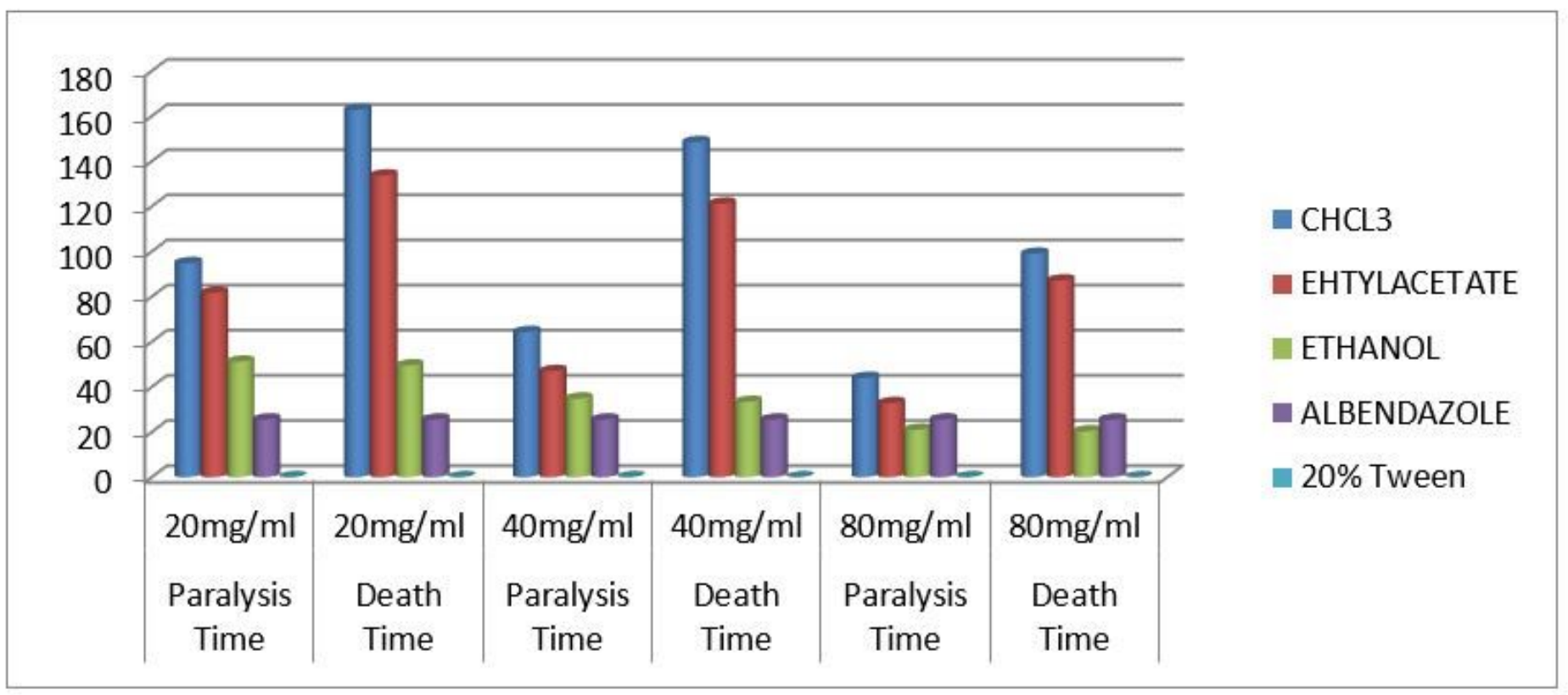

Figure 1

Representations of Paralysis time (Pt) and Death time (Dt) by P. posthuma treated with CEDC, EAEDC and EEDC 


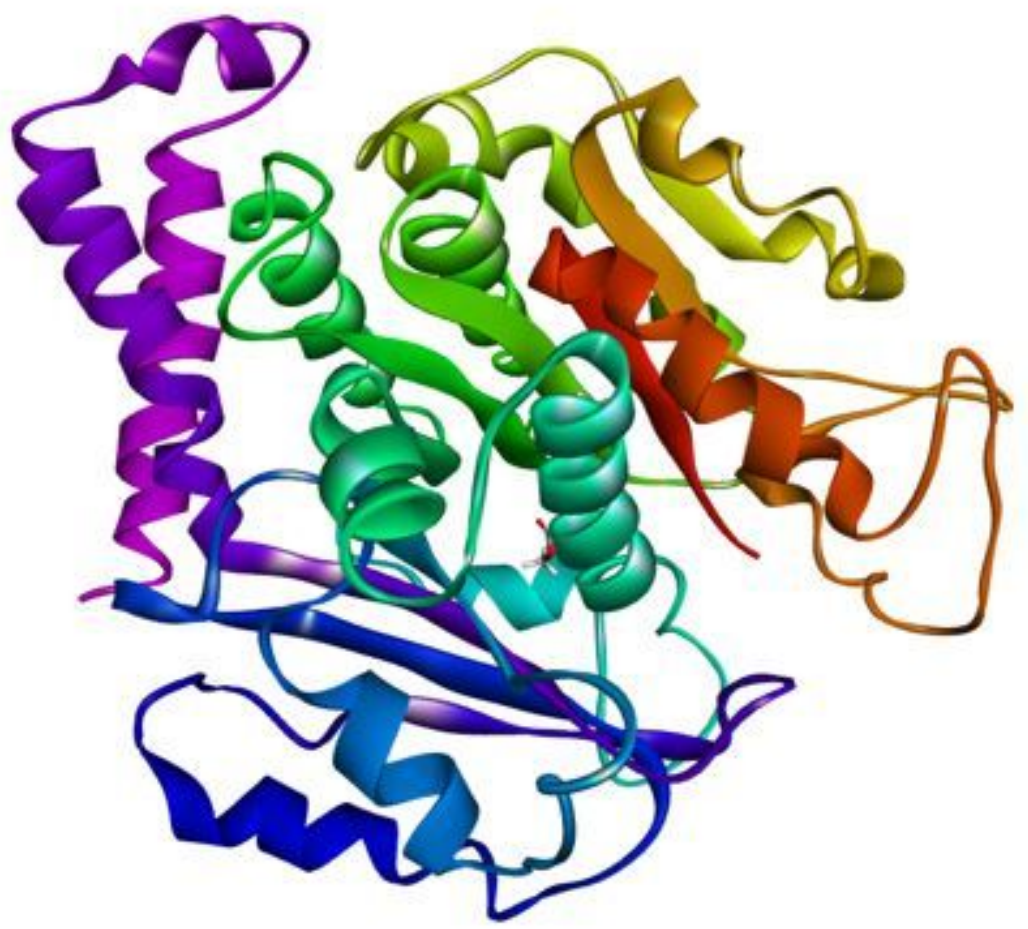

Figure 2

$\beta$-tubulin (Protein ID: 10J0) 

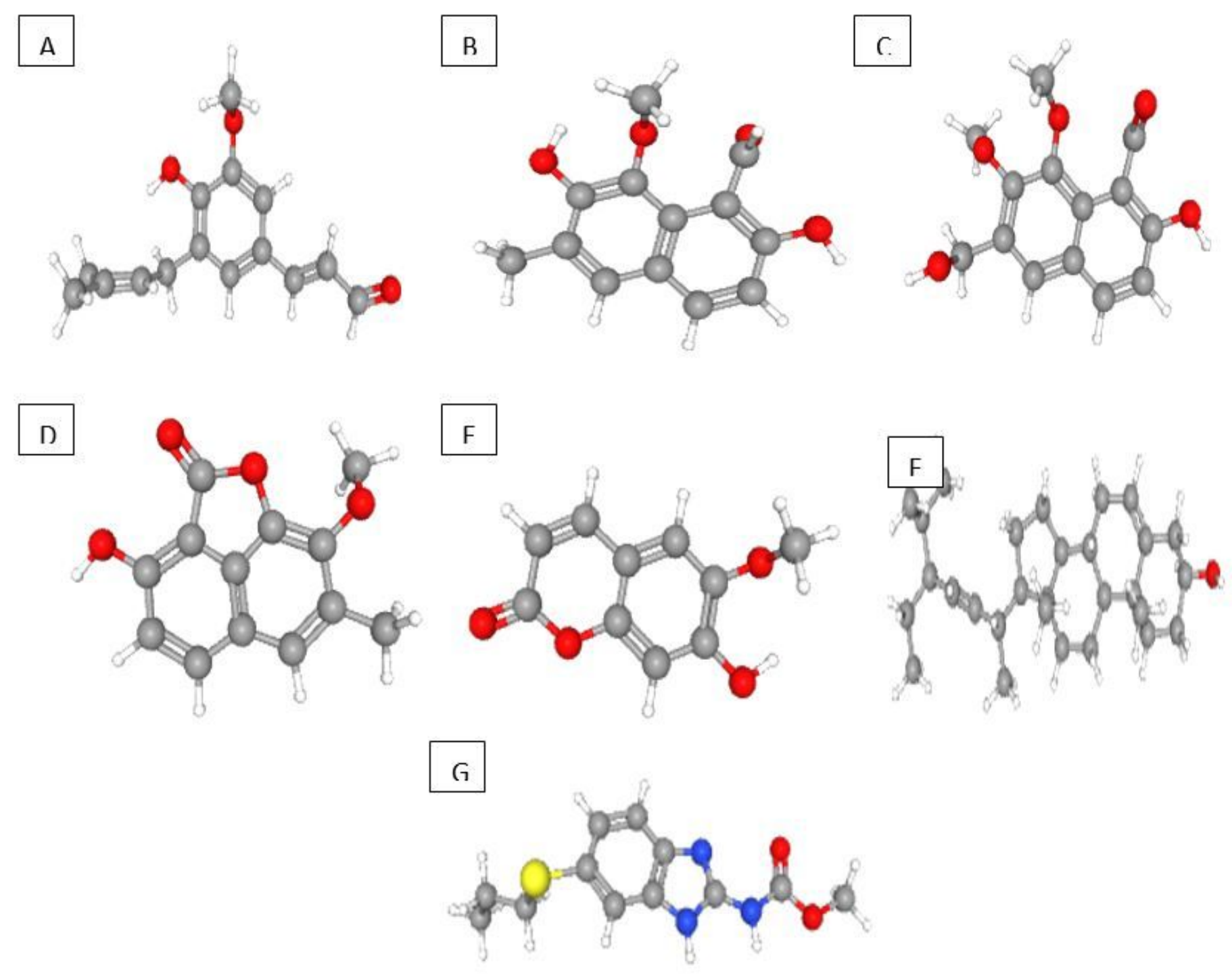

Figure 3

Chemical Structures of phytocompounds present in Dechaschistia A)Parvifloral B) Syriacusin A C) Syriacusin B D) Syriacusin C E) Scopoletin D) Stigmasterol \& G) Albendazole (Standard drug) 


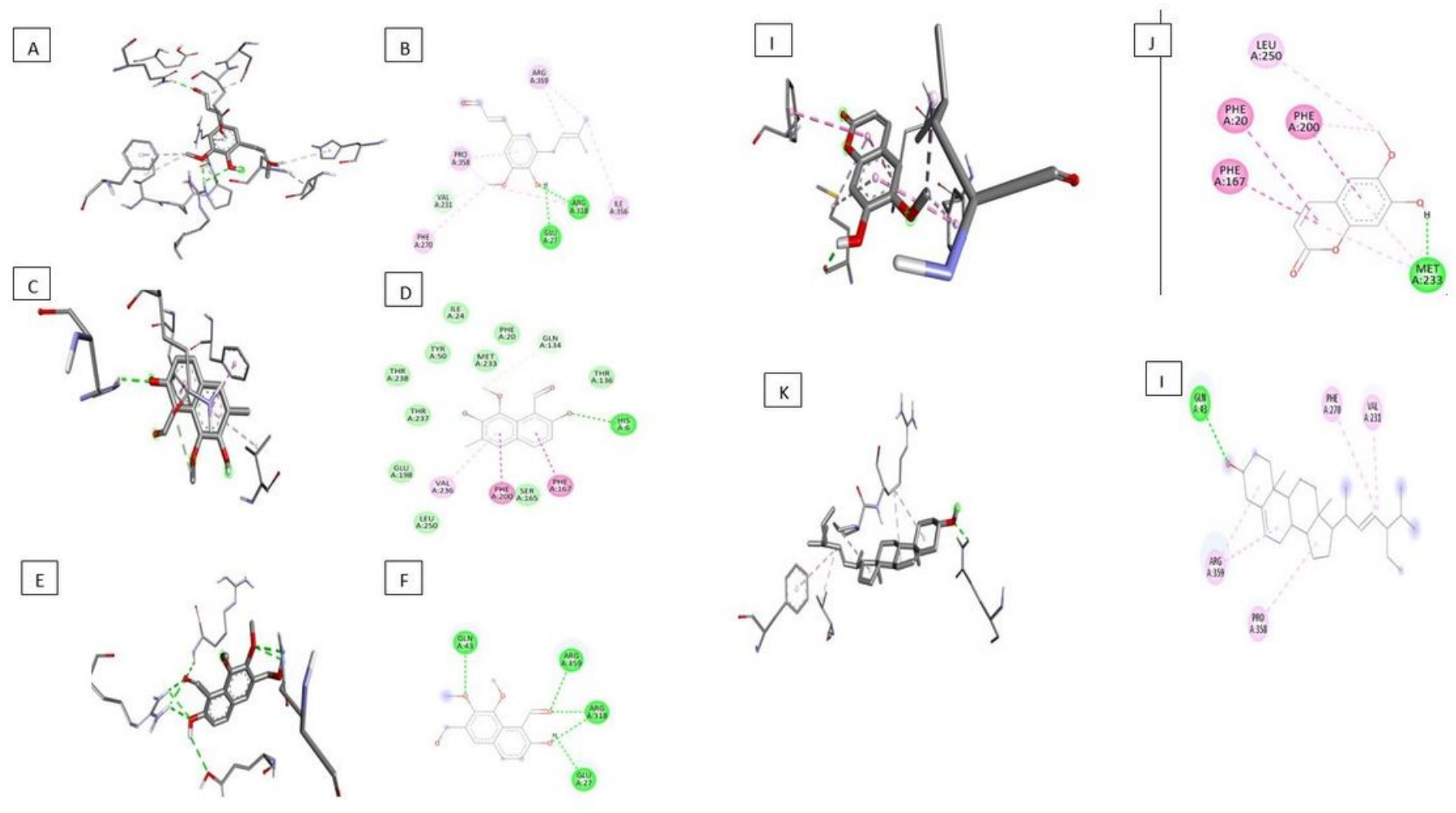

$\mathrm{G}$

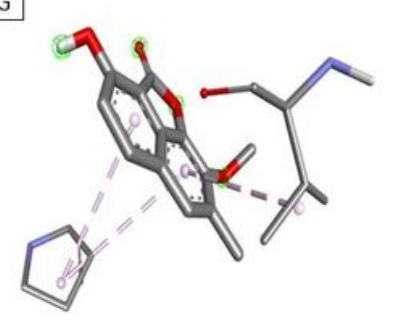

$\mathrm{H}$

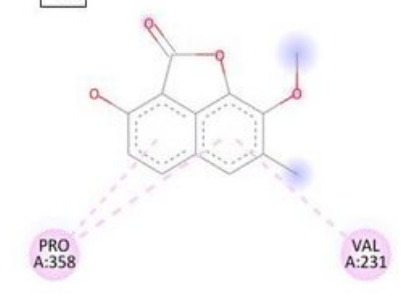

\section{Figure 4}

Visualization of 3D \& 2D images of molecular docking between $\beta$-tubulin (Protein) and 6 phytocompounds present in Dechaschistia A,B)Parvifloral C,D ) Syriacusin A E,F) Syriacusin B G,H) Syriacusin I,J) Scopoletin K,L) Stigmasterol 